\title{
Chronic Intermittent Atrial Standstill with Intraatrial Block and Split Atrial Potentials
}

\author{
Eiji Oda, Yoshifusa Aizawa, Toshiyuki Shibuya, \\ Minoru Murata, Yutaka Arai, Takefumi Ozawa and \\ Akira Shibata
}

The First Department of Internal Medicine, Niigata University School of Medicine, Niigata 951

\begin{abstract}
Oda, E., Aizawa, Y., Shibuya, T., Murata, M., Arai, Y., Ozawa, T. and Shibata, A. Chronic Intermittent Atrial Standstill with Intraatrial Block and Split Atrial Potentials. Tohoku J. exp. Med., 1984, 143 (4), 431-439— A 24year-old male with chronic atrial standstill underwent an electrophysiologic study. No atrial activity was recorded from the right atrium which did not respond to stimulation with up to 10 volts. After the administration of atropine, non-localized split atrial potentials appeared, and intraatrial phase 4 block and atrial flutter with intraatrial $2: 1$ block were observed. The atrium then responded to electrical stimulation (less than 2 volts). Persistent sinus node activity with intraatrial block was found during post-pacing atrial pauses. ——atrial standstill ; phase 4 block; sick sinus syndrome
\end{abstract}

Atrial standstill is usually classified into two types ; transient and persistent types (Bellet 1971). The former type has been observed in drug intoxications such as digitalis or quinidine, hyperkalemia, during acute myocardial infarction or after open heart surgery (Waldo et al. 1972). The latter type is uncommon, often accompanied by syncopal attacks or brain embolism (Wada et al. 1966 ; Allenswarth et al. 1969 ; Baldwin et al. 1973 ; Tanaka et al. 1975 ; Kurokawa et al. 1975 ; Harris and Baldwin 1976 ; Nordenberg et al.1976). Rarely spontaneous recovery of atrial excitability may be found (Bayne et al. 1980).

However, some cases lacking $\mathrm{P}$ waves on their surface ECGs may have localized atrial activity when studied by the intraatrial electrograms, which are called pseudo-silent atrium (Narula 1975), or sinoventricular conduction (Khan et al. 1973; Ross et al. 1976). Certain cases reported as partial atrial standstill may also lack $\mathrm{P}$ waves in the ECGs (Effendy et al. 1979; Levy et al. 1980).

In the patient reported here, $\mathrm{P}$ waves had been observed only intermittently in the ECGs for about ten years and brain embolism occurred at the age of 24 years. This report presents some interesting electrophysiologic findings.

Received for publication, December 5, 1983. 


\section{Case Report}

A 24-year-old man was admitted to our hospital for the study of bradyarrhythmias. The family history was not contributory. He had a syncopal attack at the age of 14 years for the first time but was not treated. When he was seventeen years old, a bradycardia was noted during a routine health examination at school and he was referred to a hospital. On admission, bradycardia (39 bpm), mild hepatomegaly and elevations in GOT (362 KU), GPT (470 KU), LDH (850 IU/ liter) were observed. His ECGs showed junctional bradycardia without $\mathrm{P}$ waves. Intermittently, sinus rhythm resumed but with sinoatrial block or prolonged PR intervals. He received isoproterenol which was discontinued because of frequent occurrences of atrial flutter. The hepatomegaly and hepatic dysfunction were normalized with rest and he was discharged.

At the age of 21 years, he was admitted to a hospital for enteritis and bradycardia was again noted. He had no cardiac symptoms and could perform hard physical exercise including mountain climbing and skiing.
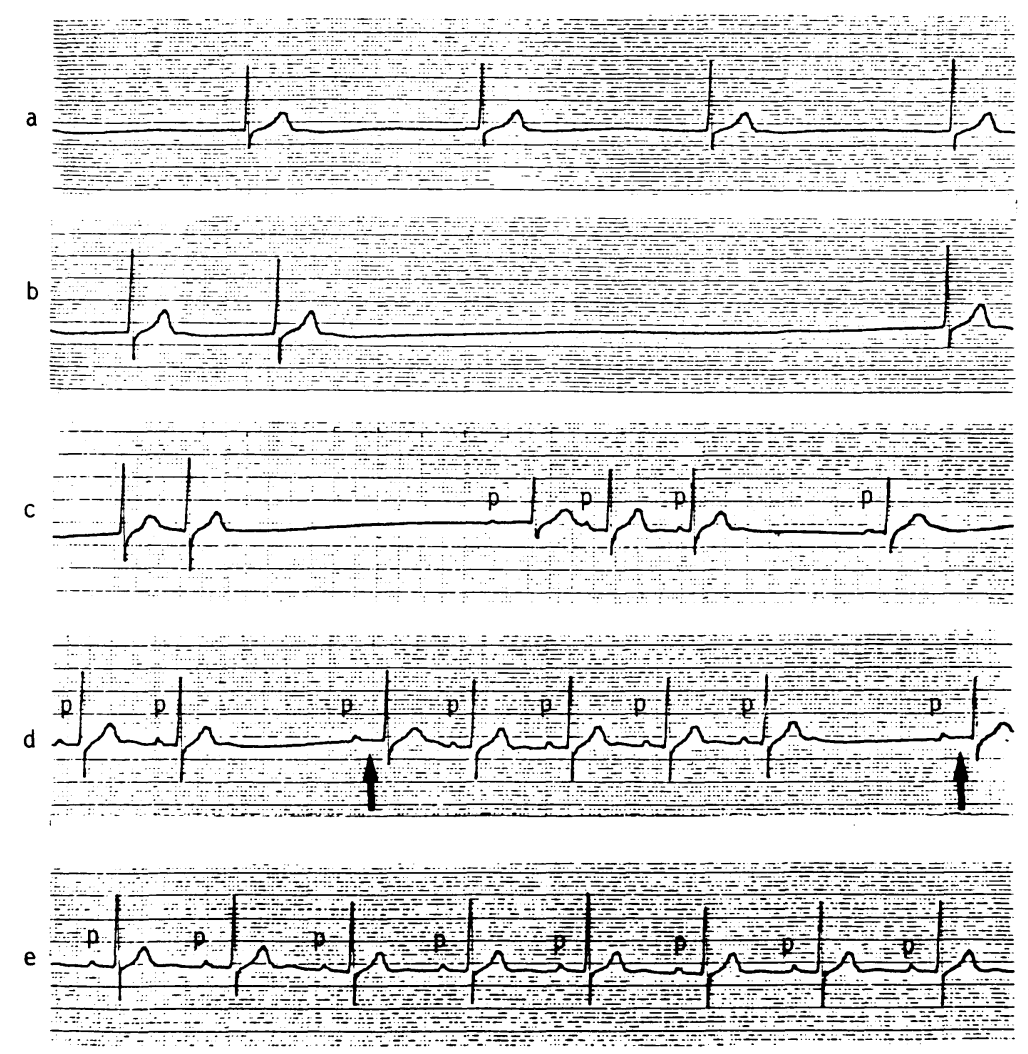

Fig. 1. A 24-hr ambulatory ECG recording. The PR intervals are paradoxically prolonged after a long PP interval as indicated by arrows in Fig. d. 
Two weeks before the present admission to our hospital (at the age of 24), he developed hemiparesis and was admitted to a hospital where CT scanning showed a lesion due to brain embolism. Physical examinations on admission revealed slow irregular pulses and slight cardiomegaly, but no sign of pulmonary congestion. No jugular venous distension or edema was detected. Left hemiparesis was apparent. A chest X-ray film showed moderate cardiomegaly (cardiothoracic ratio $=60 \%$ ) but the lungs were normal. In a catheterization study, intracardiac and pulmonary pressures were normal. However, the right atrial pressure and the pulmonary arterial wedge pressure revealed no A waves. Serum electrolytes were normal $(\mathrm{Na}=137 \mathrm{mEq} /$ liter, $\mathrm{K}=4.4 \mathrm{mEq} /$ liter, $\mathrm{Ca}=4.7 \mathrm{mEq} /$ liter $)$. Other laboratory data included mild hepatic dysfunction (total bilirubin $=1.0 \mathrm{mg} / 100$ $\mathrm{ml}, \mathrm{GOT}=42 \mathrm{KU}, \mathrm{GPT}=112 \mathrm{KU}, \mathrm{LDH}=1,172 \mathrm{IU} /$ liter, Al-Pase $=150 \mathrm{IU} /$ liter). WBC was 15,300 and CRP was positive. These abnormal findings normalized soon after the admission.

ECG on admission showed junctional bradycardia without $\mathrm{P}$ wave. QRS complexes and ST-T segement were normal. $24 \mathrm{hr}$ ambulatory ECG monitoring showed multiple arrhythmia including regular junctional rhythm (Fig. 1a), prolonged ventricular pauses (Fig. 1b), irregular supraventricular rhythm with or without $\mathrm{P}$ waves (Fig. 1C), sinoatrial block (Fig. 1d), and sinus rhythm with prolonged PR intervals (Fig. le). It was noted that immediately after atrial pause, $\mathrm{PR}$ interval was paradoxically prolonged as indicated by arrows in Fig. 1d, suggesting phase 4 block.

\section{Electrophysiologic Study}

Informed consent was obtained and two quadripolar electrode catheters (USCI) with inter-electrode distance of $10 \mathrm{~mm}$ were introduced from the right femoral vein. Both the distal and the proximal pairs of electrodes were used for recordings of atrial and His bundle electrograms. Another tripolar electrode was inserted from the left internal jugular vein and used for stimulation. Three surface ECG leads (I, aVf and Vl) and four intracardiac leads were simultaneously recorded. Filter settings for intracardiac recordings were all $50-1000 \mathrm{~Hz}$.

When the study started, no electrical activity was recorded in several sites of the right atrium or near the pulmonary valve. The right atrium was stimulated electrically up to the output of 10 volts with a pulse width of $1 \mathrm{msec}$ in these sites, but no response was elicited. Atropine $1.0 \mathrm{mg}$ was given intravenously and low amplitude atrial activity appeared first in the high lateral atrium. This atrial activity gradually increased in amplitude and split into two components, and then began to conduct to the His bundle. At this time, surface ECGs showed no P wave. When $\mathrm{P}$ waves appeared in surface ECGs, the split atrial activity was found from high to mid-lateral right atrium and in the high atrial septal area as reported before (Oda et al. 1983). Atrial activity was not observed in the low lateral right atrium (Fig. 2). A low amplitude potential was seen immediately 


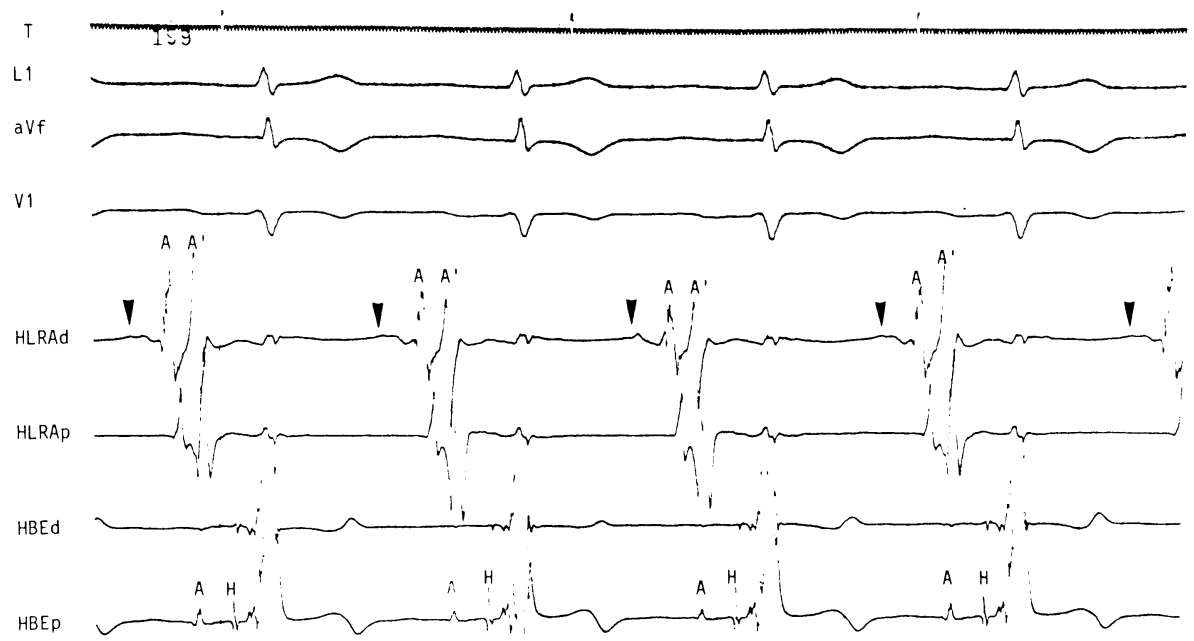

Fig. 2. Restoration of the atrial activity after the administration of atropine. Split atrial activities are seen in the high lateral right atrium. $\mathrm{T}=1,000 \mathrm{msec}$ time lines, $\mathrm{HLRA}=$ the high lateral right atrium, $\mathrm{HBE}=$ his bundle electrogram, $-\mathrm{d}=$ distal pair of the electrodes, $-\mathrm{p}=$ proximal pair of the electrodes, $\mathrm{A}=$ atial activity, $\mathrm{A}^{\prime}=$ the latter component of split atrial activity, $\mathrm{H}=\mathrm{His}$ bundle potential.

before each split potential in the high lateral right atrium, as shown by an arrowhead in Figs. 2 and 3. After atropine, the right atrium responded to 2 volts1 msec pulse currents. "Sinus node recovery time" was abnormally prolonged after overdrive pacing (3,500 msec in Fig. 4). But low frequency potential, suggesting local nodal activity (Cramer et al. 1978) was regularly and reproducibly observed in the high lateral right atrium, which persisted during postpacing atrial pause (arrows in Fig. 4) and seemed to be conducted to the atrium (arrowheads in Fig. 4). The intraatrial conduction of the first post-pacing atrial activity from the high lateral right atrium to His bundle region was markedly prolonged or blocked as shown in Fig. 5a. Therefore, the corresponding PR intervals in the surface ECGs were prolonged, though the preceding PP intervals were long, suggesting phase 4 block. At times, atrial flutter occurred following this post-pacing intraatrial block. During atrial flutter, intraatrial $2: 1$ block was seen between the high lateral right atrium and His bundle region (Fig. 5b). As shown in Fig. 5b, an intermittent $1: 1$ conduction of the atrial potential to the His bundle region was observed.

After the study, the patient received dicumarol and a ventricular pacemaker was implanted. Cardiac size was normal on his discharge.

\section{Discussion}

This patient had demonstrated atrial standstill for more than 10 years. Futhermore, no atrial activity was found in the control state. Electrical stimula- 

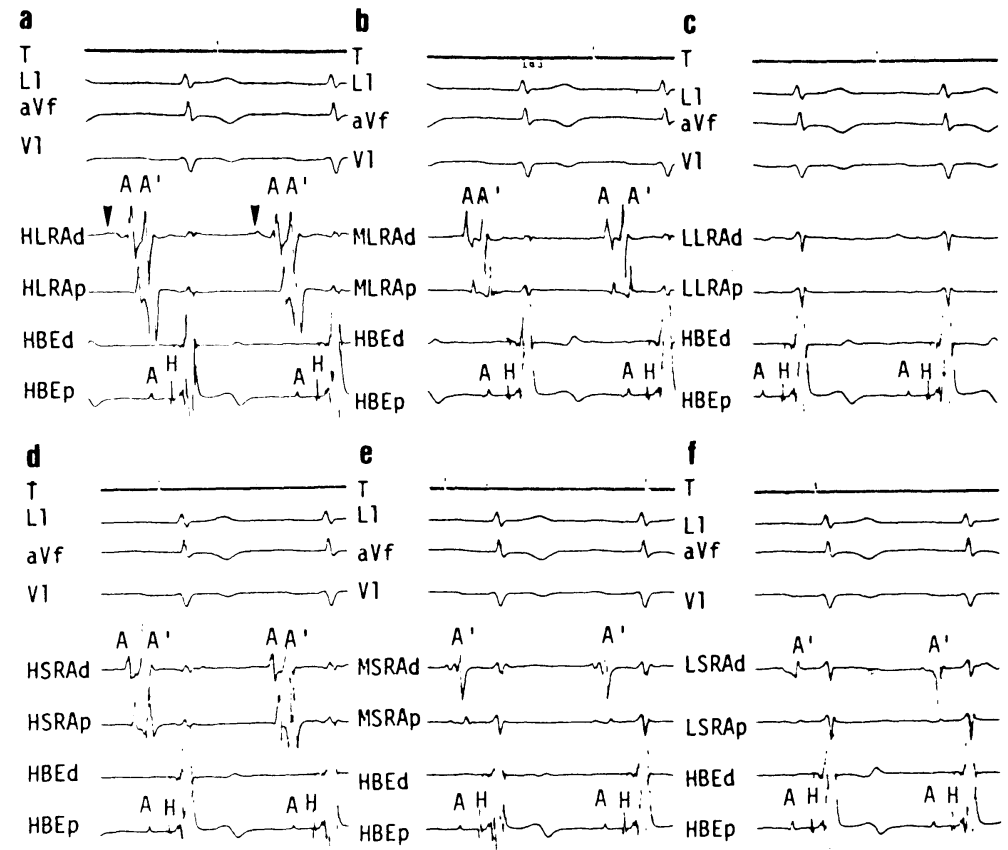

Fig. 3. Intraatrial mapping. The split atrial activity is not localized to the high lateral right atrium. No intrinsic deflection is seen in the low lateral region. MLRA = the mid-lateral right atrium, LLRA = the low lateral right atrium, HSRA = the high septal right atrium, MSRA=the mid-lateral right atrium, LSRA = the low septal right atrium. Other abbreviations are the same as Fig. 2.

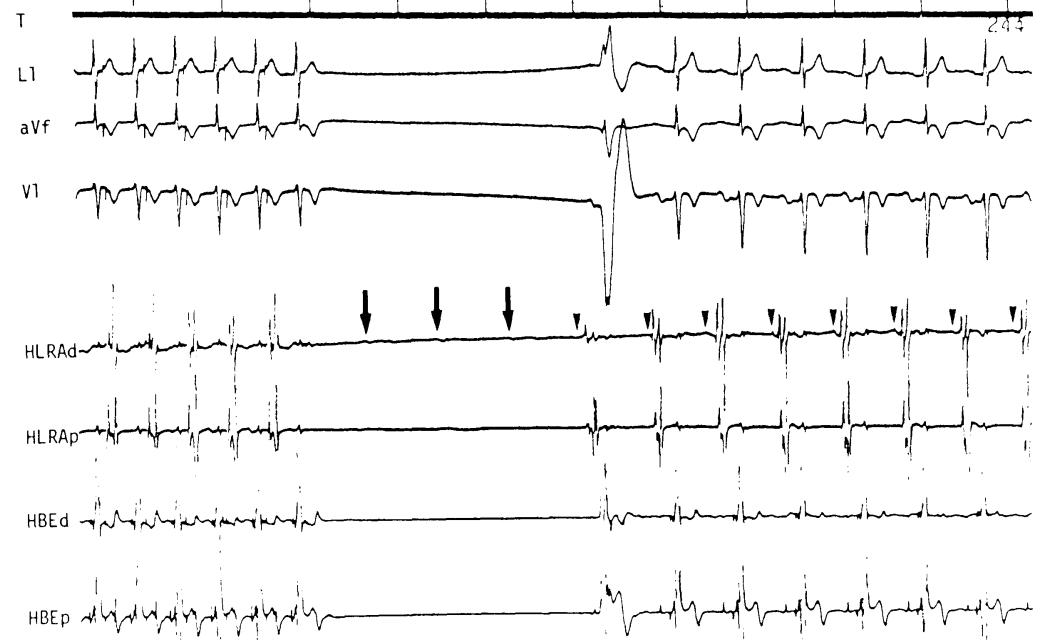

Fig. 4. Overdrive suppression test. The first intrinsic deflection appeared 3,500 msec after the end of pacing. Low-frequency, small-amplitude potentials are seen before the appearance of the intrinsic deflections in the high lateral right atrium (indicated by arrows). Abbreviations are the same as Fig. 2. 
a

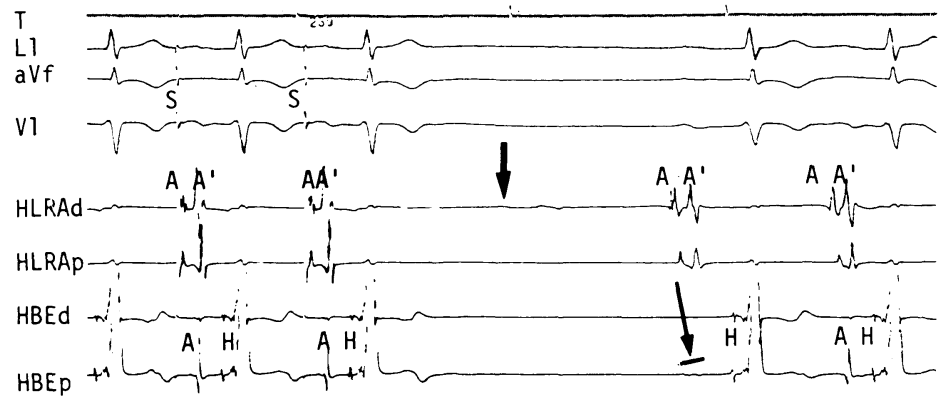

b
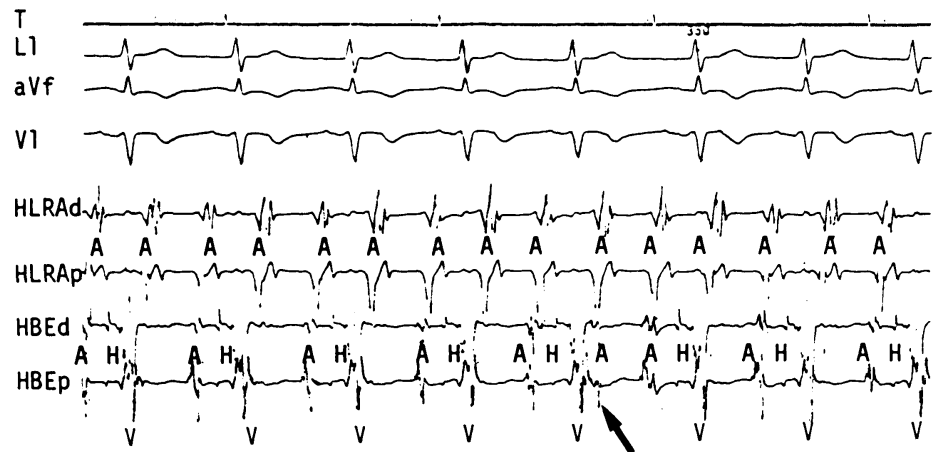

Fig. 5. a : Intraatrial phase 4 block. A vertical arrow indicates a low frequency, smallamplitude potential which suggests localized perinodal activity. An oblique arrow with perpendicular bar shows intraatrial phase 4 block between the high lateral right atrium and the His bundle region. Abbreviations are the same as Fig. 2 .

b : Intraatrial $2: 1$ block during atrial flutter. An arrow indicates accidental 1: 1 conduction of the atrial activity to the His bundle region. Abbreviations are the same as Fig. 2.

tion up to 10 volts- 1 msec failed to provoke atrial depolarization. Interesting findings were found after atropine administration; split atrial potentials, phase 4 block and persistent local activity confined to high lateral region of the right atrium during the post-pacing atrial arrest.

As to the split potentials, Davis and Hoffman (1963) and Wagner et al. (1966) observed two component deflections in canine atria in situ. They thought that these double deflections were due to the presence of specialized conducting fibers. Two component action potentials were also observed in small strip of human atria when it was cooled to $27^{\circ} \mathrm{C}$ (Sleator and de Gubareff 1964 ; Fabiato and Fabiato 1971). Fabiato and Fabiato (1971) considered that the splitting of action potentials was related to conduction delay and non-homogenous excitation from hypothermia-induced hypopolarization.

In clinical electrophysiologic studies, reports concerning split atrial potentials are few (Oda et al. 1983; Gillete et al. 1974; Csapo et al. 1978; Akhtar et al. 
1978). Akhtar et al. (1978) reported two cases with two component deflections in the right atrial electrogram and they considered these splitting reflected localized intraatrial conduction delays. Non-localized splitting of the atrial activity was found by us before in a case of brady-tachy syndrome (Oda et al. 1983). We speculated that the splittings resulted from intraatrial block in the diseased atrium (Hordof et al. 1976). In the present case, such disturbances in conduction may have also played a role in the genesis of split atrial potentials.

Although patients with tachycardia-dependent intraatrial block has been reported (Castellanos et al. 1972; Narula et al. 1972; Leier and Schaal 1977), phase 4 block (Rosenbaum et al. 1976) in the atrium is not. A prolongation of PR intervals after a long PP interval in the preceding beat was observed in the ambulatory ECG (Fig. 1d). This prolongation may result from phase 4 intraatrial block. Such intraatrial block was observed in the postpacing beat (Figs. 4 and 5a). Following this intraatrial phase 4 block, bradycardia and/or tachycardia were found in this case.

Hariman et al. (1980) recorded a low frequency and low amplitude deflection that corresponded with phase 4 and phase 0 of the transmembrane action potential of the sinus nodal pacemaker cell group by low pass filters. In the present case, the low frequency potential was easily recorded from the high lateral right atrium without low pass filters. It could be a local sinus nodal potential or it may result from slow response and conduction in perinodal atrial fibers with hypopolarized resting membrane potential (Hordof et al. 1976). The prolongation of the "sinus node recovery time" seen in Fig. 4 was not due to true sinus pause, but to the intraatrial block in the vicinity of sinus node, as recently reported by Asseman et al. (1983). Such perinodal block can be one spectrum of the sick sinus syndrome.

\section{References}

1) Akhtar, M., Caracta, A.R., Lau, S.H., Gilbert, C.J. \& Damato, A.N. (1978) Demonstration of intraatrial conduction delay, block, gap and reentry. A report of two cases. Circulation, 58, 947-955.

2) Allenswarth, D.C., Rice, G.J. \& Lowe, G.W. (1969) Persistent atrial standstill in a family with myocardial disease. Amer. J. Med., 47, 775-784.

3) Asseman, P., Bergin, B., Dessy, D., Vilarem, D., Durand, P., Delmotte, C., Sarkis, E. H., Lekieffre, J. \& Thery, C. (1983) Persistent sinus nodal electrograms during abnormally prolonged postpacing atrial pauses in sick sinus syndrome in humans: sinoatrial block vs overdrive suppression. Circulation, 68, 33-41.

4) Baldwin, B.J., Talley, R.C., Johnson, C. \& Nutter, D.O. (1973) Permanent paralysis of the atrium in a patient with fascioscapulohumeral muscular dystrophy. Amer. $J$. Cardiol., 31, 649-653.

5) Bayne, E.J., Chandramouli, B., Cancilla, P.A. \& Lauer, R.M. (1980) Familial prolonged atrial standstill presenting in infancy. J. Pediat., 97, 953-956.

6) Bellet, S. (1971) Clinical Disorders of the Heart Beat. Lea \& Febiger, Philadelphia, p. 153.

7) Castellanos, A., Jr., Inenger, R., Agha, A.S. \& Castillo, C.A. (1972) Wenckebach phenomenon within the atria. Brit. Heart J., 34, 1121-1126.

8) Cramer, M., Hariman, R.J., Boxer, R. \& Hoffman, B.F. (1978) Electrograms from the 
canine sinoatrial pacemaker recorded in vitro and in situ. Amer. J. Cardiol., 42, 939946.

9) Csapo, G., Weisswange, A., Kalusche, D. \& Schnellbacher, K. (1978) Partial atrial standstill in sick sinus syndrome: intraatrial and AV nodal block with short PR interval. Europ. J. Cardiol., 8, 617-627.

10) Davis, L. \& Hoffman, B.F. (1963) Evidence for specialized pathways in atrial excitation. Fed. Proc., 22, 246. (Abstract)

11) Effendy, F.N., Bolognesi, R., Bianchi, G. \& Visioli, O. (1979) Alternation of partial and total atrial standstill. J. Electrocardiol., 12, 121-127.

12) Fabiato, A. \& Fabiato, F. (1971) The two components of the human atrial action potential. Circulat. Res., 29, 296-305.

13) Gillete, P.C., El-seid, G.M., Sivarajan, N., Mullin, C.E., Willium, R.L. \& McNamara, D.G. (1974) Electrophysiological abnormalities after Mustard's operation for transposition of the great arteries. Brit. Heart J., 36, 186-191.

14) Hariman, R.J., Krongrad, E., Boxer, R.A., Weiss, M.B., Steeg, C.M. \& Hoffman, B.F. (1980) Method for recording electrical activity of the sinoatrial node and automatic atrial foci during cardiac catheterization in human subjects. Amer. J. Cardiol., 45, $775-781$.

15) Harris, C.L. \& Baldwin, B.J. (1976) Permanent atrial paralysis. J. Electrocardiol., 9, 81-84.

16) Hordof, A.J., Edie, R., Malm, J.R., Hoffman, B.F. \& Rosen, M.R. (1976) Electrophysiologic properties and response to pharmacologic agents of fibers from diseased human atria. Circulation, 54, 774-779.

17) Khan, A.H., Haider, R., Boughner, D.R., Oakley, C.M. \& Goodwin, J.F. (1973) Sinus rhythm with absent $\mathrm{P}$ wave in advanced rheumatic heart disease. Amer. J. Cardiol., 32, 93-97.

18) Kurokawa, A., Kurita, A, Kasai, G. \& Kimura, E. (1975) Persistent atrial standstill. Report of three cases. J. Electrocardiol., 8 357-362.

19) Leier, C.V. \& Schaal, S.F. (1977) Dissimilar atrial rhythms: A patient with interatrial block. Brit. Heart J., 39, 680-684.

20) Levy, S., Pouget, B., Bemurat, M., Lacaze, J.-C., Clementy, J. \& Bricaud, H. (1980) Partial atrial electrical standstill : Report of three cases and review of clinical and electrophysiological features. Europ. Heart J., 1, 107-116.

21) Narula, O.S. (1975) His Bundle Electrocardiography and Clinical Electrophysiology, F.A. Davis Co., Philadelphia, p. 68.

22) Narula, O.S., Runge, M. \& Samet, P. (1972) Second-degree Wenckebach type AV block due to block within the atrium. Brit. Heart J., 34, 1127-1136.

23) Nordenberg, A., Varghese, P.J. \& Nugent, E.W. (1976) Spectrum of sinus node dysfunction in two siblings. Amer. Heart J., 91, 507-512.

24) Oda, E., Shibuya, T., Satoh, F., Aizawa, Y., Arai, Y., Ozawa, T.\& Shibata, A. (1983) Split atrial activity in a man with brady-tachy syndrome. Tohoku J. exp. Med., 139., 141-150.

25) Rosenbaum, M.B., Lazzari, J.O. \& Elizari, M.V. (1976) The role of phase 3 and phase 4 block in clinical electrophysiology. In: The Conduction System of the Heart, edited by H.J.J. Wellens, K.I. Lei \& M.J. Janse, H.E. Stenfert Krouse, Leiden, pp. 126-142.

26) Ross, A.M., Proper, M.C. \& Aornson, A.L. (1976) Sinoventricular conduction in atrial standstill. J. Electrocardiol., 9, 161-164.

27) Sleator, W. \& de Gubareff, T. (1964) Transmembrane action potentials and conduction of human atrial muscle. Amer. J. Physiol., 206, 1000-1014.

28) Tanaka, H., Atsuchi, Y., Tanaka, N., Nishi, S., Kanehisa, T., Tanaka, S. \& Taira, A. (1975) Persistent atrial standstill due to atrial inexcitability : An electrophysiological and histological study. Jap. Heart J., 16, 639-653. 
29) Wada, M., Takada, C. \& Mise, J. (1966) A case report of atrial standstill. Jap. Circulat. J., 30, 543-553.

30) Wagner, M.L., Lazzara, R., Weiss, R.M. \& Hoffman, B.F. (1966) Specialized conducting fibers in the interatrial band. Circulat. Res., 18, 502-518.

31) Waldo, A.L., Vitikainen, K.J., Kaiser, G.A., Bowman, F.O., Jr. \& Malm, J.R. (1972) Atrial inexcitability (atrial quiescence) : Recognition and treatment following openheart surgery. Circulation, 46, 690-697. 